\title{
Arthroscopic Treatment of Patients with Arthrofibrosis Following Total Knee Replacement
}

\author{
DANIEL OLTEAN DAN ${ }^{1,2 *}$, GABRI J OZSEF ZSOLT ${ }^{1}$, DRAGOS APOSTU ${ }^{1,2}$, MIHAI GHEORGHE PAIUSAN ${ }^{1,2}$, CRISTIAN PAUL DAN ${ }^{1,2}$, \\ CIPRIAN ALIN BARDAS ${ }^{1,2}$, GHEORGHE TOMOAIA ${ }^{1,2,3}$, HOREA RARES CIPRIAN BENEA ${ }^{1,2}$ \\ ${ }^{1}$ Orthopedics and Traumatology Clinic Alexandru Radulescu, 47-49 General Traian Mosoiu, 400000, Cluj Napoca, Romania \\ 2Iuliu Hatieganu University of Medicine and Pharmacy, Department of Orthopedics and Traumatology, 36 Eroilor Str., 400129.,Cluj \\ Napoca, Romania \\ ${ }^{3}$ Academy of Romanian Scientists, 54 Splaiul Independentei, 050085, Bucharest, Romania
}

\begin{abstract}
The main objective of the current study was to evaluate the success of arthroscopic arthrolysis treatment of patients with knee stiffness after total knee arthroplasty. Six patients who underwent arthroscopic arthrolysis were evaluated retrospectively, all of them being treated conservatively before going for surgery. Results showed significant improvement of range of motion and Knee Society Score at the latest follow up compared to the preoperative values. This study concludes that arthroscopic arthrolysis is an effective and reproductible technique for the treatment of knees stiffness after total knee arthroplasty.
\end{abstract}

Keywords: Knee Stiffness, Arthrofibrosis, Arthroplasty, Arthroscopy, Arthrolysis

Total knee arthroplasty (TKA) is one of the most successful orthopedic procedures [1] that reliably alleviates pain and restores function in patients with knee osteoarthritis. The results are considered excellent if postoperative, patients can perform a knee flexion $>1250$ and they have an extension deficit $<50$ [2]. Success rates for this operation are high, but 3-4\% of the patients who underwent a TKA, are going to develop arthrofibrosis post-surgery that can pe painful and decreases range of motion (ROM). [3] Arthrofibrosis, defined as abnormal scarring of the joint in which the formation of dense fibrous tissue and tissue metaplasia prevents normal ROM [4], and drastically reduces quality of life of those affected individuals. Prevention of knee stiffness should be started from the TKA surgery by limiting the amount of bone resected, correct positioning of prosthetic components with appropriate ligament balancing, restoring the mechanical and anatomical axes of the lower limb, and proper prosthesis design [5]. Psychological factors such as excessive postoperative pain, which prevent appropriate rehabilitation treatment, as well as poor patient motivation, should not be omitted. Hutchinson et al has defined knee stiffness that requires surgery, a flexion of the knee below 750 and a flexion contracture greater than $15^{\circ}[6]$.

Non-operative treatment includes pain therapy, physical therapy and manipulation under anesthesia [7], which must be done with great delicacy to prevent damage of prosthesis components or even fractures [8]. If these options fail, surgical treatment is required, that can be done either by classic (open) or arthroscopic surgery [9], or in some cases requiring revision arthroplasty [10].

In this study, were evaluated the results of arthroscopic arthrolysis performed in patients with TKA, with knee flexion below $75^{\circ}$ or flexion contracture greater than $15^{\circ}$ at 3 months post-TKA, after the conservative treatment (NSAIDs and aggressive physiotherapy) failed. The main objective was to evaluate the effectiveness of this minimal invasive surgical technique, by ROM improvement and functional outcome, assessed by Knee Society Score (KSS). The hypothesis of our study was that arthroscopic arthrolysis could restore an adequate range of motion and improve functional outcome for patients with arthrofibrosis after TKA.

\footnotetext{
* email: olteandandaniel@yahoo.com, Phone: 0746235466
}

\section{Experimental part}

A retrospective review of all cases with postoperative arthrofibrosis of the knee following total knee arthroplasty (TKA) was performed, in the Orthopedics and Traumatology Clinic of Cluj-Napoca, between May 2016 and December 2017.

The inclusion criteria for undergoing arthroscopic arthrolysis were knee flexion below $75^{\circ}$ or flexion contracture greater than $15^{\circ}$ at 3-months post-TKA, after the conservative treatment (NSAIDs and aggressive physiotherapy) failed. The exclusion criteria from the study were knee stiffness secondary to other causes such as infection, mechanical malalignment, loosening of the implants, posttraumatic ligament instabilities or osseous lesions around the knee (mid-shaft, distal femoral fractures, tibial plateau fractures, patellar fractures).

Patients demographics data relevant for the study were age, gender, body mass index (BMI), preoperative and follow-ups range of motion and functional scores using the Knee Society Score (KSS) at 1, 3 and 6 months and at 1year postoperative.

According to data from Table 1, in the present study were included 6 patients of $66.5 \pm 7.66$ (53-74) years old, $M / F=$ $1 / 5$. The average time between TKA and arthroscopic arthrolysis was $7.33 \pm 1.86$ months (5-9). The average body mass index (BMI) of the patients was $30.89 \pm 4.04 \mathrm{~kg} / \mathrm{m}^{2}$ (26.33-36.20), two patients had a BMI under $30 \mathrm{~kg} / \mathrm{m}^{2}$ and four patients had BMI over $30 \mathrm{~kg} / \mathrm{m}^{2}$. Intraoperatively the surgical time was assessed and postoperatively, the amount of drained blood, the hospitalization period and the complications that occurred were recorded. Preoperatively and postoperatively (at 1, 3 and 6 months and 1-year follow-up) the ROM and KSS were evaluated. It was further assessed whether there was any correlation between KSS increase at 1-year follow-up and BMI, age and the time interval between TKA and arthroscopic arthrolysis.

Therefore, patients presented with a preoperative ROM of $62.50 \pm 10.84$ (45-75) and at 1-year follow-up they had a total ROM of $101.70 \pm 7.52$ (90-110), with an average improvement of $40.830 \pm 6.64$ (30-45). The mean follow-up of patients was $11 \pm 4.5$ months (6-18). By the last followup, two patients (33.3\%) were lost from evidences, at 6 months postoperatively. 
The surgical steps were always performed in a systematic manner. Regional epidural anesthesia was performed, and a nonsterile tourniquet was applied on the proximal thigh. The leg was then examined for ROM. The standard anterolateral (AL) and anteromedial (AM) portals were performed. Examination of suprapatellar pouch was done in knee extension and scar tissue was resected (fig. 1, left), and any debris or loose bodies were removed. In some cases, medial or lateral suprapatellar portals were used to facilitate release of the patella in cases of tight patella. The knee was then flexed to 90 degrees, possible intraoperatively in 4 cases, and the Hoffa fat pad was removed until a good visualization was obtained. The prosthesis components were also examined for loosening or malalignment. Anterior interval release was then performed when scar tissue or cyclops lesion were found, and the medial and lateral gutters (fig. 1, right) were debrided, followed by loose bodies removal ifneeded. Finally, it was performed a gradual and reasonable mobilization of the knee under anesthesia and ROM was finally assessed.

Postoperatively, each patient followed a standard rehabilitation program. All the patients started an intensive course of physiotherapy postoperatively including continuous passive motion (CPM), started at 6 hours postoperative, for 45 minutes to 1 hour, three times a day and continued for at least one week. Also, they performed a muscular strengthening program for reinforcement of quadriceps and hamstrings muscles and they started early assisted weight bearing, that was progressively converted to full bearing as tolerated. After the patients were discharged, they continued physical therapy in a specialized rehabilitation center, twice or three times per week, for at least 4-6 weeks postoperative.

Statistical analyses were performed using GraphPad Prism 6.0 for Windows. Descriptive statistics were per- formed for all parameters, each being expressed by mean \pm standard deviation and extreme values of the group. Study groups were compared by one-way ANOVA with post-hoc Tukey test. Pearson coefficient was used to test correlations between the variables. The significance limit was established as $p<0.05$.

\section{Results and discussions}

The mean surgery time for arthroscopic arthrolysis was $92 \pm 20.05 \mathrm{~min}$ (70-120), and the average amount of blood loss, evaluated from the drainage bags was $162.5 \pm 118.8$ $\mathrm{mL}(75-400)$. Patients were hospitalized in average $9 \pm$ 3.48 days (5-15), being a case that required 15 days of hospitalization due to postoperative bleeding $(400 \mathrm{~mL}$ in the drainage bag), which required a longer clinical followup. There were no major complications following arthroscopic arthrolysis, no cases of infection or thromboembolic phenomena. Instead there were two cases (33.3\%) who had a hemarthrosis at 2 weeks post-surgery that causes pain and limitation of knee range of motion, which required evacuation through articular puncture of $42.5 \mathrm{~mL}$ (35-50 mL) bloody fluid. No patient in the current study required revision or second surgeries.

The time elapsed from total knee arthroplasty to arthroscopic arthrolysis was $7.33 \pm 1.86$ months (5-9). The literature suggests that this procedure should preferably be performed within the first 9 months, the best results being obtained within the first 7 months [11]. Other authors prefer to perform this minimal invasive technique between 8 weeks and 6 months after physical therapy failure [12], in these cases being correlated with a significant increase in functional scores. After a year, the functional scores and ROM are far inferior [11]. The advantages of this technique are the control of postoperative bleeding and it does not require further immobilization and under suitable pain con-

Table 1

PATIENTS DEMOGRAPHICS AND CLINICAL DATA

\begin{tabular}{|c|c|c|c|c|c|c|c|c|}
\hline & $\begin{array}{c}\mathrm{M} / \\
\mathrm{F}\end{array}$ & $\begin{array}{c}\text { AGE } \\
\text { (YEARS) }\end{array}$ & $\begin{array}{c}\text { BMI } \\
\left(\mathrm{KG} / \mathrm{M}^{2}\right)\end{array}$ & $\begin{array}{l}\text { PRE-OP } \\
\operatorname{ROM}\left({ }^{\circ}\right)\end{array}$ & $\begin{array}{l}\text { 1YEAR } \\
\text { POST-OP } \\
\text { ROM }\left(^{\circ}\right)\end{array}$ & $\begin{array}{l}\text { PRE-OP } \\
\text { (KSS) }\end{array}$ & $\begin{array}{c}\text { POST- } \\
\text { OP } \\
\text { (KSS) }\end{array}$ & $\begin{array}{c}\text { FOLLOW-UP } \\
\text { (MONTHS) }\end{array}$ \\
\hline 1. & $\mathrm{M}$ & 74 & 32.03 & $15^{\circ}-80^{\circ}$ & $0^{\circ}-110^{\circ}$ & 70 & 84 & 6 \\
\hline 2. & $\mathrm{~F}$ & $70^{-}$ & 26.44 & $15^{\circ}-85^{\circ}$ & $5^{\circ}-105^{\circ}$ & 64 & 82 & 12 \\
\hline 3 . & $\mathrm{F}$ & 63 & 36.19 & $10^{\circ}-75^{\circ}$ & $0^{\circ}-110^{\circ}$ & 68 & $85^{-}$ & 6 \\
\hline 4. & $\mathrm{~F}$ & 67 & 30.12 & $20^{\circ}-65^{\circ}$ & $5^{\circ}-90^{\circ}$ & 58 & 72 & 12 \\
\hline 5. & $F^{-}$ & 72 & $34.20^{\circ}$ & $15^{\circ}-90^{\circ}$ & $5^{\circ}-105^{\circ}$ & 66 & 82 & 12 \\
\hline 6. & $\mathrm{~F}^{--}$ & 53 & $26.33^{-}$ & $10^{\circ}-65^{\circ}$ & $-5^{\circ}-95^{\circ}$ & 62 & 83 & 18 \\
\hline $\begin{array}{c}\text { MEAN } \pm \\
\text { SD }\end{array}$ & & $66.5 \pm 7.66$ & $30.89 \pm 4.03$ & $\begin{array}{l}14.17^{\circ}- \\
76.67^{\circ}\end{array}$ & $2.5^{\circ}-102.5^{\circ}$ & $\begin{array}{c}64.67 \pm \\
4.32\end{array}$ & $\begin{array}{c}81.33= \\
4.71\end{array}$ & $11 \pm 4.5$ \\
\hline
\end{tabular}

Abbreviations: $\mathrm{M}=$ male; $\mathrm{F}=$ female; Pre-op = preoperative; $p o s t-o p=$ postoperative; $R O M=$ range of motion; $K S S=\mathrm{Knee}$

Society Score

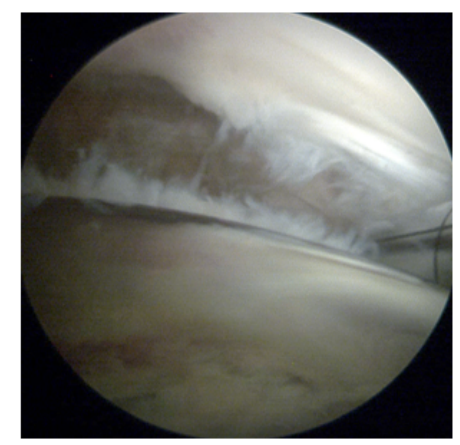

REV.CHIM.(Bucharest) 69 No. $11 \bullet 2018$

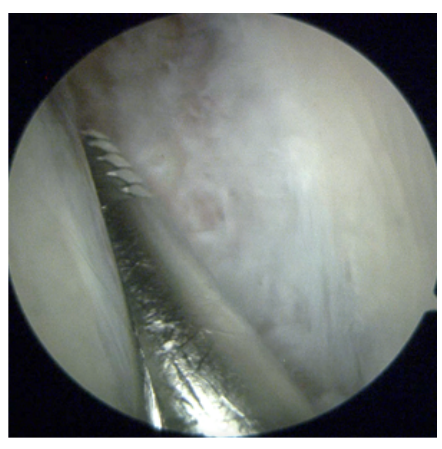

http://www.revistadechimie.ro
Fig. 1. Arthroscopic view of the suprapatellar pouch (left) and lateral gutter (right) during the arthroscopic arthrolysis of the intraarticular adhesions with a shaver 
a.

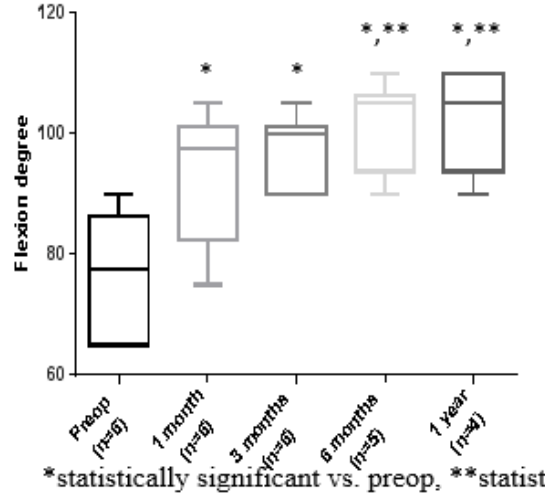

trol can be started ROM recovery.

Figure 2a shows a statistically significant improvement of flexion degree at all follow-ups compared to preoperative values. In addition, significantly higher values compared to flexion values at 1 month were seen at 6 months and 1 year. Flexion of the knee increased at 1-year follow-up at $102.5^{\circ} \pm 8.21$ (95-110), with an average improvement of $25.83^{\circ} \pm 7.36$ (15-35), significantly higher compared to preoperative values, $76.67^{\circ} \pm 10.33$ (65-90), $p<0.001$. Postoperative, at the lastfollow up, all patients achieved a flexion of at least 90 degrees. Moreover, figure $3 b$ shows a statistically significant decrease of flexion contracture at all follow-ups compared to the preoperative values. It improved by $12.5^{\circ} \pm 2.73(10-15)$ at 1 - year follow - up, at $1.67^{\circ} \pm 4.08(-5-5)$, significantly lower compared to preoperative values, $14.17^{\circ} \pm 3.74(10-20), p<0.001$. Three of the patients $(n=3, .50 \%)$ remained with a residual flexion contracture of $5^{\circ}$ at one year postoperative.

Patients mobility and ROM were increased significantly in all cases at 1 year after arthroscopic arthrolysis and rehabilitation. Flexion degree improved and contracture in flexion diminished progressively at 1-year postoperative compare to preoperative values. A meta-analysis that included 12 studies of arthroscopic arthrosis after TKA, showed an improvement in the ROM between 18.5 and $60^{\circ}$ [9] Considerable variations between patients' outcome are given by the small number of patients included in studies, being difficult for statistical evaluation. Furthermore, in this type of surgery, some authors claim that it is difficult to correct the flexion contracture due to the difficult access to the posterior capsule adhesions, which leads to the limitation of the extension [3]. Thus, the surgical technique can be supplemented with the use of posterior approach [13], technically more difficult, but which offers a good exposure of the posterior capsule of the knee.

Additionally, according to figure 3, a statistically significantincrease of the Knee Society Score was achieved postoperatively, at all follow-ups, compared to preoperative values. Moreover, at 3 and 6 months and 1-years follow-

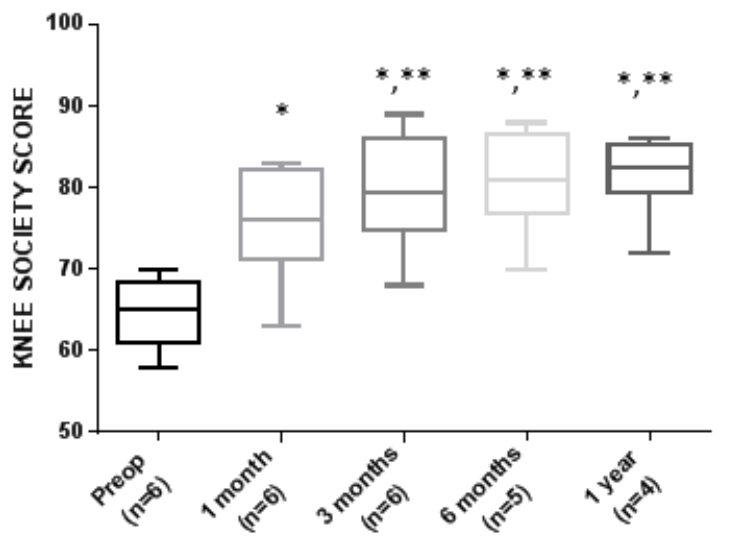

${ }^{*}$ statistically significant vs. preop, **statistically significant vs. 1 month

Fig. 3. Knee functional outcome based on Knee Society Score, preoperative and at follow-ups

ups, KSS was significantly higher compared to 1-month score. The KSS improved with an average of $16.67 \pm 2.65$ (14-21) points reaching in 1 year $81.67 \pm 5$ (72-86) points vs. $64.67 \pm 4.32$ (58-70) points, $p<0.001$, preoperative. These results correlate with those in the literature, for example the study of Hegazy A.M. from 2011 [12], which evaluated the results of 8 patients with arthrofibrosis that needed arthroscopic arthrolysis showed an improvement of KSS from 68 preoperative to 86 with an average increase of 18 points.

According to figure $4 \mathrm{~b}$, there was a strong negative correlation between patient's age and functional score $(r=$ $0.78,95 \%$ : $-0.97-0.07)$, probably due to lack of motivation of patients and lack of adherence to intensive rehabilitation treatment. There was also a moderately negative correlation between time elapsed from total knee arthroplasty to arthroscopic arthrolysis (fig. 4c) and KSS increase ( $r=-$ 0.5, 95\%: -0.90 -0.65) and a poor negative correlation between patient's BMI (fig. 4a) and KSS score increase ( $r=$ -

Table 2

DESCRIPTIVE DATA (AVERAGE, STANDARD DEVIATION AND EXTREME VALUESOF THE GROUPS) OF FLEXION DEGREE, FLEXION CONTRACTURE AND KNEE SOCIETY SCORE PREOPERATIVE AND AT FOLLOW-UP.

\begin{tabular}{|c|c|c|c|c|c|}
\hline & preoperative & $\mathrm{I}_{\text {inum }}$ & 3 musths & 6 muniths & $1_{\text {year }}$ \\
\hline Flexion degree & $76.67+ \pm 10.39[65-70]$ & $\begin{array}{l}92.3 \pm 11.25^{*}[75- \\
165]\end{array}$ & $97.5 \pm 6.124 *[90-105]$ & $1017 \pm 7.52 * * *[90-110]$ & $102.5 \pm 8.21^{* * 8}[95-110]$ \\
\hline $\begin{array}{l}\text { Flexion } \\
\text { contranture }\end{array}$ & $14.17 \pm 3.74[10-20]$ & $5 \pm 3.16 *[0-10]$ & $4.167 \pm 3.76 *[0-10]$ & $2.5 \pm 2.73^{*}[0-5]$ & $1.67 \pm 4.08^{2}[-5-5]^{-}$ \\
\hline KSS & $64.67 \pm 4.32[-8-7 \mathrm{C}]$ & $\begin{array}{l}72.67 \pm 7.2^{3} \quad[63- \\
83]\end{array}$ & $79.67 \pm 7.25^{* / k 8}[68-89]$ & $80.83 \pm 6.33 * / * 8[7]-88]$ & $8167 \pm 5^{3 / 76}[72-86]$ \\
\hline
\end{tabular}

*statistically zignificant ve prenp $(\mathrm{p} \Leftrightarrow 0,07)$; ** statistically signifiant vs 1-month (p<i 01) 

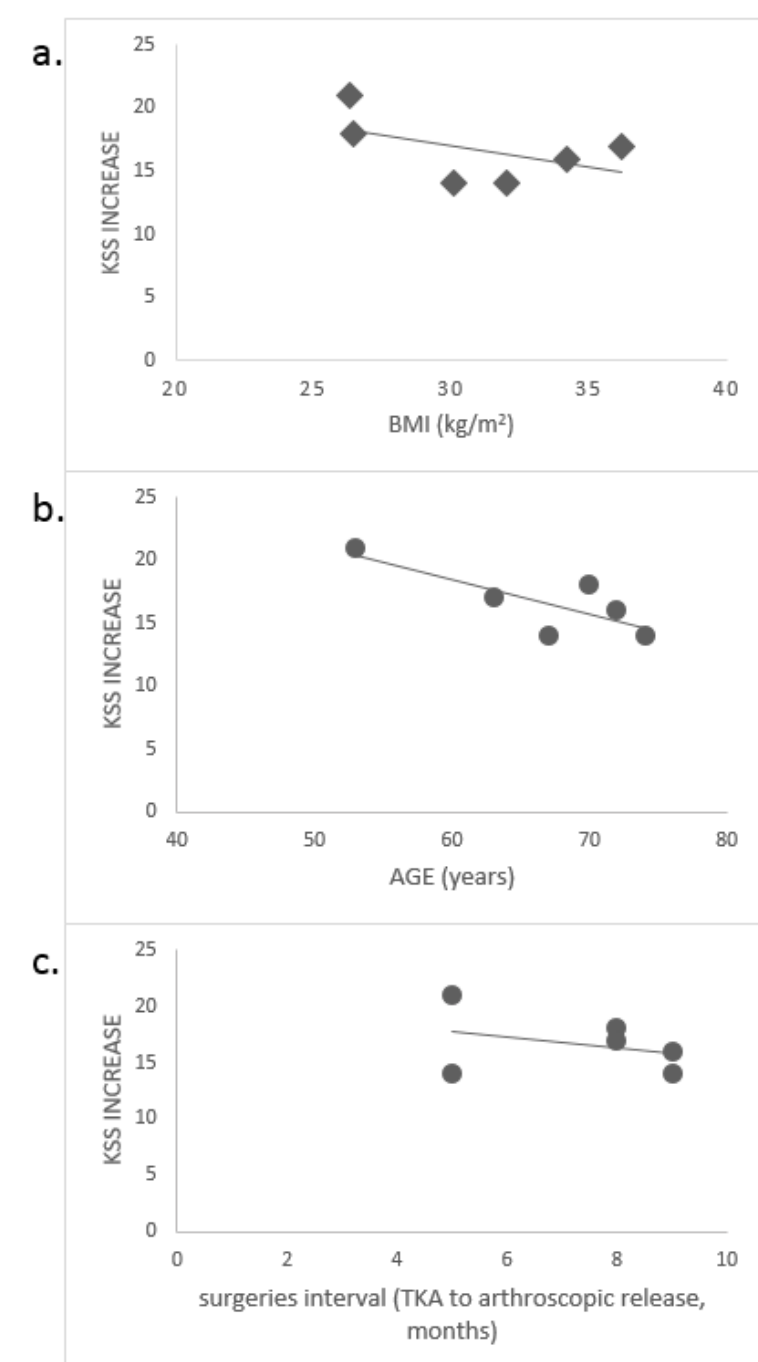

Fig. 4. Correlation charts between increasing of KSS and BMI (a.), age (b.) and the time between TKA and arthroscopic arthrolysis (c.)

0.33, 95\%: $-0.93-0.51)$. On the other hand, Schwarzkopf et al [4] concluded that patients with $\mathrm{BMI}>30 \mathrm{~kg} / \mathrm{m}^{2}$ have a significantly higher increase of ROM caused by body habitus that produces a mechanical blockage of flexion.

This study has some limitations. First of all, it was a ret- rospective study, conducted for a short period of time, including a small number of patients. Secondly, the followup period was relatively short. Furthermore, the indication for arthroscopic arthrolysis is very variable, both in terms of the limitation of the movement arc and in the optimal moment of surgery. Forming clear indications will lead to the formation of a much homogeneous group of patients from where more objective data can be obtained.

\section{Conclusions}

Arthroscopic arthrolysis is an effective and reproductible technique for the treatment of knee stiffness after total knee arthroplasty, with excellent results in terms of range of motion improvement, and functional outcome assessed by Knee Society Score.

\section{References}

1. H. MARADIT KREMERS DR. LARSON, CS CROWSON, WK KREMERS, RE WASHINGTON, CA STEINER, WA JIRANEK, DJ BERRY, J. Bone J oint Surg. Am., 97, nr. 17, 2015, p. 1386-97.

2.H. S. YERCAN, T. S. SUGUN, C. BUSSIERE, T. AIT SI SELMI, A. DAVIES, AND P. NEYRET, Knee, 13, nr. 2, 2006 p. 111-7.

3.RAN SCHWARZKOPF, ARSANI WILLIAM, RACHEL M. DEERING, WOLFGANG FITZ, Orthopedics, 36, nr.2, 2013, e1544-48.

4.N. ABDUL, D. DIXON, A. WALKER, J. HORABIN, N. SMITH, D.J. WEIR, N.T. BREWSTER, D. J. DEEHAN, D.A. MANN, L.A. BORTHWICK, SCi. Rep., 5, nr. 1, 2015, p. 164-69.

5.J. E. ARBUTHNOT, R. B. BRINK, Knee Surgery, Sport. Traumatol. Arthrosc., 18, nr. 3, 2010, p. 346-351.

6.J. R. M. HUTCHINSON, E. N. PARISH, M. J. CROSS, J. Bone J oint Surg. $\mathrm{Br} ., 87-\mathrm{B}, \mathrm{nr} .10,2005$, p. 1357-1360.

7.R. MOHAMMED, S. SYED, N. AHMED, Ann. R. Coll. Surg. Engl., 91, nr. 3, 2009, p. 220-223.

8.K. ISSA, B. H. KAPADIA, M. KESTER, H. S. KHANUJ A, R. E. DELANOIS, M. A. MONT, J. Arthroplasty, 29, nr. 3, 2014, p. 548-52.

9.S. E. FITZSIMMONS, E. A. VAZQUEZ, M. J. BRONSON, Clin. Orthop. Relat. Res., 468, nr. 4, 2010, p. 1096-1106.

10.P. E. SCRANTON, J. Arthroplasty, 16, nr. 4, 2001, p. 428-35.

11.J. ACHALANDABASO, J. ALBILLOS, Arthrosc. J . Arthrosc. Relat. Surg., 9, nr. 6, 1993, p. 685-690.

12.J. R. STEADMAN, J. L. DRAGOO, S. L. HINES, K. K. BRIGGS, Am. J. Sports Med., 36, nr. 9, 2008, p. 1763-1769.

13.H. ASANO, T. MUNETA, I. SEKIYA, Knee Surgery, Sport. Traumatol. Arthrosc., 16, nr. 11, 2008, p. 999-1000.

$\overline{\text { Manuscript received: } 20.08 .2018}$ 